\section{JURNAL EKONOMI EFEKTIF}

ISSN : $2622-8882$, E-ISSN : 2622-9935

Jurnal Ekonomi Efektif, Vol. 3, No. 4, Juli 2021

@ Prodi Manajemen Fakultas Ekonomi Universitas

Pamulang

\title{
PENGARUH GAYA KEPEMIMPINAN DAN BUDAYA KERJA TERHADAP KINERJA KARYAWAN PADA MCDONALD'S CABANG FATMAWATI
}

\author{
Nariah $^{1 *}$, Retno Japanis Permatasari², Muhammad Musyfiq Salami ${ }^{3}$ \\ Universitas Pamulang, Tangerang Selatan, Banten, Indonesia \\ dosen02459@unpam.ac.id*
}

\begin{abstract}
Manuskrip: Mei -2021 Ditinjau: Mei -2021; Diterima: Mei-2021; Online: Juli-2021; Diterbitkan: Juli-2021
\end{abstract}
\begin{abstract}
ABSTRAK
Penelitian ini bertujuan untuk mengetahui pengaruh gaya kepemimpinan dan budaya kerja terhadap kinerja karyawan pada McDonald's Cabang Fatmawati. Metode yang digunakan adalah explanatory research dengan teknik analisis menggunakan analisis statistik dengan pengujian regresi, korelasi, determinasi dan uji hipotesis. Hasil penelitian ini gaya kepemimpinan berpengaruh signifikan terhadap kinerja karyawan sebesar $47,1 \%$, uji hipotesis diperoleh thitung $>\mathrm{t}$ tabel atau $(7,192>2,002)$. Budaya kerja berpengaruh signifikan terhadap kinerja karyawan sebesar 44,6\%, uji hipotesis diperoleh $t$ hitung $>t$ tabel atau $(6,828>2,002)$. Gaya kepemimpinan dan budaya kerja secara simultan berpengaruh signifikan terhadap kinerja karyawan dengan persamaan regresi $\mathrm{Y}=7,464+0,421 \mathrm{X} 1+0,418 \mathrm{X} 2$ dan kontribusi pengaruh sebesar 62,0\%, uji hipotesis diperoleh $\mathrm{F}$ hitung > F tabel atau $(46,584>2,770)$.
\end{abstract}

\section{Kata Kunci: Gaya Kepemimpinan, Budaya Kerja, Kinerja Karyawan}

\begin{abstract}
This study aims to determine the effect of leadership style and work culture on employee performance at McDonald's Fatmawati Branch. The method used is explanatory research with analytical techniques using statistical analysis with regression, correlation, determination and hypothesis testing. The results of this study that leadership style has a significant effect on employee performance by 47.1\%, hypothesis testing is obtained t count > t table or $7.192>$ 2.002). Work culture has a significant effect on employee performance by 44.6\%, hypothesis testing is obtained $t$ count $>$ t table or $(6.828>2.002)$. Leadership style and work culture simultaneously have a significant effect on employee performance with the regression equation $Y=7,464+0,421 X 1+0,418 X 2$ and the contribution of influence is $62.0 \%$, hypothesis testing is obtained $F$ count $>$ F table or $(46.584>2.770)$.
\end{abstract}

Keywords: Leadership Style, Work Culture, Employee Performance 


\section{PENDAHULUAN}

\section{A. Latar Belakang}

Dalam kehidupan sehari-hari manusia tidak pernah lepas dari kehidupan berorganisasi, karena pada kodratnya manusia merupakan makhluk sosial yang cenderung untuk selalu hidup bermasyarakat. Hal ini nampak baik di dalam kehidupan rumah tangga, organisasi kemasyarakatan, bahkan pada saat seseorang memasuki dunia kerja. Seseorang tersebut akan berinteraksi, dan masuk menjadi bagian dalam organisasi tempat bekerjanya. Didalam dunia kerja pasti tak lepas kaitannya dengan kepemimpinan, budaya organisasi serta kinerja yang ada pada semua karyawan. Manajemen menurut Terry dalam Athoillah (2013:16) menjelaskan bahwa "Manajemen merupakan suatu proses khas yang terdiri dari tindakan-tindakan perencanaan, pengorganisasian, penggerakan, dan pengendalian untuk menentukan serta mencapai tujuan melalui pemanfaatan sumber daya manusia lainnya"

Menurut Nawawi dalam Gaol (2014:44), "Sumber Daya Manusia adalah orang yang bekerja dan berfungsi sebagai aset organisasi atau perusahaan yang dapat dihitung jumlahnya (kuatitatif), dan SDM merupakan potensi yang menjadi penggerak organisasi. Sumber daya manusia (SDM) memegang peranan yang sangat dominan dalam aktivitas atau kegiatan perusahaan. Berhasil atau tidaknya suatu perusahaan tergantung pada kemampuan sumber daya manusianya dalam menjalankan tugas-tugas yang diberikan."

Sumber daya manusia merupakan salah satu faktor penting dalam menunjukan keberhasilan setiap perusahaan, karena hampir seluruh kegiatan operasional dijalankan oleh manusia. Oleh karena itu perusahaan harus membentuk sumber daya manusia yang terampil dan ahli di bidangnya sehingga tujuan perusahaan dapat tercapai sesuai dengan waktu yang telah ditetapkan.

Menurut Hasibuan (2014:113)."Gaya kepemimpinan adalah cara seorang pemimpin mempengaruhi perilaku bawahan, agar mau bekereja sama dan bekerja secara produktif untuk mencapai tujuan organisasi". Karyawan harus mampu membina dan memotivasi bawahannya untuk bekerja sama dan bekerja secara efektif dalam mencapai sasaran perusahaan.

Gering Supriyadi dan Tri Guno dalam Rina Puspita Dewi (2014:31) "Budaya kerja adalah suatu falsafah dengan didasari pandangan hidup nilai-nilai yang menjadi sifat, kebiasaan, dan juga pendorong yang dibudayakan dalam suatu kelompok dan tercermin dalam sikap, menjadi perilaku, cita-cita, pendapat, pandangan, serta tindakan yang yang terwujud sebagai kerja." Budaya kerja berkaitan erat dengan komponen organisasi lainnya, seperti struktur dan strategi perusahaan. Artinya, untuk memperoleh hasil sinergi yang optimal bagi perkembangan perusahaan harus ada keselarasan antara strategi (bagaimana perusahaan mencapai tujuan), struktur (bagaimana bentuk perusahaan yang dapat mendukung pencapaian tujuan). Jadi, budaya kerja yang benar-benar dikelola sebagai alat manajemen akan berpengaruh dan menjadi pendorong bagi karyawan untuk berprilaku positif, dedikatif, dan produktif. Nilai-nilai budaya itu tidak tampak tetapi merupakan kekuatan yang mendorong perilaku untuk menghasilkan efektivitas kinerja karyawan.

Kinerja seorang karyawan merupakan hal yang bersifat individual, karena setiap karyawan mempunyai tingkat kemampuan yang berbeda-beda dalam mengerjakan tugasnya. Kinerja menurut Veitzhal (2014:309) menjelaskan pengertian "Kinerja merupakan suatu fungsi dari motivasi dan kemampuan untuk menyelesaikan tugas atau pekerjaan seseorang sepatutnya memiliki derajat kesediaan dan tingkat kemampuan tertentu, juga merupakan perilaku nyata yang ditampilkan setiap orang sebagai prestas kerja yang dihasilkan oleh karyawan sesuai dengan perannya dalam upaya perusahaan 
untuk mencapai tujuannya."

McDonald's cabang Fatmawati, adalah salah satu sebuah restoran cabang McDonald's dimana restauran tersebut merupakan restoran cepat saji yang selalu menjamin mutu produk-produknya, memberikan pelayanan yang memuaskan, menawarkan kebersihan dan keamanan produk pangan yang terus mengalami perkembangan kearah yang terus menguntungkan sebagai sebuah brand, serta terus mengembangkan sistem operasional MCDonald's kearah yang lebih baik lagi lewat teknologi dan inovasi.

Gaya kepemimpinan yang diterapkan di McDonald's cabang Fatmawati Jakarta Selatan idialnya bersifat demokratis dimana pemimpin dalam suatu bagian harus dapat melaksanakan kegiatan secara berjenjang di area manajer kemudian diteruskan kepada supervisor, team leader, yang melibatkan staff dan pelaksana. Sedangkan yang berkaitan dengan pemutusan kebijaksanaan dilakukan oleh kepala pemimpin yang saling bekerja sama dengan kepala bidang dan kepala staff. Pekerjaan dilakukan dengan tanggung jawab antar pimpinan dan bawahan yang saling berkesinambungan.

Berdasarkan pada pra survey diperoleh informasi bahwa dalam kondisi riilnya tidak semua elemen idial seorang pemimpin mampu dilaksanakan dengan semestinya artinya masih ada aspek yang terkoreksi, hal ini apabila tidak ada pembenahan maka bukan tidak mungkin akan mengakibatkan menurunnya kinerja karyawan menjadi tidak optimal. Berikut ini data tabel pra survey kondisi kepemimpinan periode 2017 sebagai berikut:

Tabel 1. Data Pra Survei Kepemimpinan McDonald's Cabang Fatmawati

\begin{tabular}{|c|c|c|c|c|}
\hline No & $\begin{array}{c}\text { Faktor penyebab rendahnya kinerja terkait } \\
\text { kepemimpinan }\end{array}$ & Target & Persentase & Ket \\
\hline 1 & Terbuka dan efektif dalam bekerja & $100 \%$ & $55,6 \%$ & Kurang \\
\hline 2 & Komunikasi dengan bawahan baik & $100 \%$ & $58,2 \%$ & Kurang \\
\hline 3 & Mengayomi bawahan sebagai mitra & $100 \%$ & $63,6 \%$ & Cukup \\
\hline 4 & Mau menerima kritikan dan saran & $100 \%$ & $64,3 \%$ & Cukup \\
\hline 5 & Bertanggung jawab pada pekerjaan & $100 \%$ & $53,2 \%$ & Kurang \\
\hline 6 & Pribadi yang dapat dicontoh & $100 \%$ & $56,1 \%$ & Kurang \\
\hline & Rata-rata & $\mathbf{1 0 0 \%}$ & $\mathbf{5 8 , 5 \%}$ & Kurang \\
\hline
\end{tabular}

Ket: $<50 \%=$ Buruk, 51-60\% =Kurang, 61-70\% = cukup, 71-80 = Baik, 81-100\% = Sangat baik

Sumber: McDonald's Cabang Fatmawati, 2018

Berdasarkan data pada tabel di atas, memperlihatkan bahwa kondisi kepemimpinan pada tataran masih terkoreksi dimana secara keseluruhan hanya mencapai 58,5\% dari kondisi idial yang semestinya dapat dilakukan dengan optimal. Seorang pemimpin tidak hanya dituntut tegas dan sigap dalam menghadapi setiap persoalan yang ada, melainkan juga harus mengerti akan keinginan atau kebutuhan setiap karyawannya. Pemimpin yang bijaksana dan baik harus dapat memberikan kepuasan kepada para bawahannya dan selalu berusaha memperhatikan gairah atau semangat kerja mereka.

Keberhasilan suatu organisasi ditentukan oleh adanya komunikasi yang baik dan cara pemimpin menggunakan gaya kepemimpinan dalam mengatur bawahannya untuk mencapai kinerja yang diinginkan, komunikasi disini adalah komunikasi antara karyawan dan antara karyawan dengan atasan. Komunikasi yang baik adalah jalinan pengertian antara pihak yang satu dengan pihak yang lain sehingga apa yang dikomunikasikan dapat dimengerti, difikirkan dan dilaksanakan. Jalinan komunikasi mutlak diperlukan dalam suatu oragnisasi karena dalam setiap kegiatannya membutuhkan ketepatan informasi yang sesuai dengan keperluan dan informasi tersebut dapat diperoleh khususnya melalui komunikasi dan pemilihan kepemimpinan yang baik. 
Tabel 2. PT Rekso Nasional Food McDonald's Cabang Fatmawati Data Penilaian Kinerja Karyawan

\begin{tabular}{|c|c|c|c|c|c|}
\hline Tahun & JK & $\begin{array}{c}\text { Target Pertahun } \\
(\mathrm{Rp})\end{array}$ & $\begin{array}{c}\text { Pencapaian } \\
(\mathrm{Rp})\end{array}$ & $\begin{array}{c}\text { Presentase } \\
\text { Pencapaian }\end{array}$ & Keterangan \\
\hline 2016 & 50 & 14.400 .000 .000 & 8.951 .589 .700 & $62.2 \%$ & Tidak Tercapai \\
\hline 2017 & 50 & 14.400 .000 .000 & 7.636 .133 .140 & $53.0 \%$ & Tidak Tercapai \\
\hline 2018 & 55 & 14.400 .000 .000 & 8.695 .981 .300 & $60.4 \%$ & Tidak Tercapai \\
\hline 2019 & 58 & 14.400 .000 .000 & 8.146 .180 .070 & $56.6 \%$ & Tidak Tercapai \\
\hline 2020 & 60 & 14.400 .000 .000 & 8.125 .839 .270 & $56.4 \%$ & Tidak Tercapai \\
\hline \multicolumn{2}{|c|}{ Rata-rata } & 14.400 .000 .000 & 8.311 .144 .696 & $57.7 \%$ & Tidak Tercapai \\
\hline
\end{tabular}

Sumber : McDonald's Store Management Cabang Fatmawati, 2020.

Berdasarkan data tabel di atas menunjukan bahwa jumlah total 60 karyawan, pengukuran kerja berada ditataran yang masih terkoreksi. Evaluasi yang dilakukan merupakan upaya untuk mengetahui penilaian yang dilakukan masing-masing masing kepala bagian yang kemudian dikumpulkan pada human resourdan ces depatemen (HRD) secara keseluruhan menunjukkan bahwa target yang ditetapkan oleh perusahaan tidak tercapai dan hanya mampu memperoleh capaian sebesar 57,7\%. Penilaian evaluasi kerja merupakan upaya untuk mengetahui kondisi capaian kerja , sehingga dapat diketahui apakah ada kemajuan dan kendala dalam pelaksanaan program dan kegiatan sehingga dapatt dinilai dan dipelajari (lesson learned) untuk perbaikan dimasa mendatang, serta pemberian solusi atas masalah yang ditemukan untuk tujuan peningkatan kinerja dan akuntabilitas unit kerja.

Dalam berbagai hal, evaluasi dilakukan melalui monitiring terhadap sistem yang ada. Namun, adakalanya evaluasi tidak dapat dilakukan hanya dengan menggunakan informasi yang dihasilkan oleh sistem informasi yang ada pada unit kerja. Data dari luar unit kerja juga sanagat penting sebagai bahan analisi yang dapat dipakai dalam mengukur kinerja karyawan.

Menurut Hasibuan (2012:87) "Penilaian kerja adalah kegiatan manajer untuk mengevaluasi prilaku prestasi kerja pegawai serta menetapkan kebijaksanaan". Sedangkan menurut Rivai (2012:66) "Penilaian kerja adalah proses penetapan pemahaman bersama tentang cara yang akan di capai, dan pendekatan untuk mengelola dalam waktu yang singkat ataupun lama". Bagi karyawan penilaian tersebut berperan sebagai umpan balik tentang berbagai hal seperti kemampuan, kelebihan, kekurangan dan potensinya yang pada gilirannya bermanfaat untuk menentukan tujuan perusahaan.

Berdasarkan latar belakang tersebut maka peneliti tertarik untuk mekakukan penelitian dengan judul "Pengaruh Gaya Kepemimpinan Dan Budaya Kerja Terhadap Kinerja Karyawan McDonald's Cabang Fatmawati"

\section{B. Rumusan Masalah}

1. Adakah pengaruh gaya kepemimpinan terhadap kinerja karyawan pada McDonald's Cabang Fatmawati?

2. Adakah pengaruh budaya kerja terhadap kinerja karyawan pada McDonald's Cabang Fatmawati?

3. Adakah pengaruh secara simultan gaya kepemimpinan dan budaya kerja terhadap kinerja karyawan pada McDonald's Cabang Fatmawati?

\section{Tujuan Penelitian}

1. Untuk mengetahui pengaruh gaya kepemimpinan terhadap kinerja karyawan pada McDonald's Cabang Fatmawati.

2. Untuk mengetahui pengaruh budaya kerja terhadap kinerja karyawan pada 
McDonald's Cabang Fatmawati.

3. Untuk mengetahui pengaruh secara simultan antara gaya kepemimpinan dan budaya kerja terhadap kinerja karyawan pada McDonald's Cabang Fatmawati.

\section{TINJAUAN PUSTAKA}

\section{Gaya Kepemimpinan}

Yang dimaksud gaya kepemimpinan dalam penelitian ini adalah cara seorang pemimpin mempengaruhi perilaku bawahan, agar mau bekereja sama dan bekerja secara produktif untuk mencapai tujuan organisasi. Malayu S.P. Hasibuan (2014:113). Adapun indikator yang digunakan meliputi sifat, motivatif, kebiasaan, tempramen, dan watak.

\section{Budaya Kerja}

Yang dimaksud dengan budaya kerja adalah suatu filsafah yang menjadi sifat, kebiasaan dan juga dorongan yang dibudayakan dalam suatu kelompok dan tercermin dalam sikap menjadi perilaku, cita-cita, pendapat, pandangan serta tindakan yang terwjud sebagai kerja. Menurut Supriyadi dan Guno (2014:31). Adapun indikator yang digunakan meliputi profesionalisme, norma, jarak manajemen, percaya pada rekan kerja, integrasi.

\section{Kinerja Karyawan}

Dalam penelitian ini yang dijadikan variabel dependen adalah Kinerja karyawan yang diartikan sebagai suatu ukuran dari hasil kerja atau kinerja seseorang dengan proses input sebagai masukan dan output sebagai keluarannya yang merupakan indikator dari pada kinerja karyawan dalam menentukan bagaimana usaha untuk mencapai produktivitas kerja karyawan yang tinggi dalam suatu organisasi. (Sedarmayanti, 2013:79). Adapun indikator yang digunakan meliputi: Tindakan konstruktif, Percaya pada diri sendiri, Bertanggung jawab, Mampu mengatasi masalah, Mempunyai kontribusi positif pada perusahaan

\section{METODE PENELITIAN}

\section{Populasi}

Populasi dalam penelitian ini berjumlah 60 responden atau karyawan McDonald's Cabang Fatmawati

\section{Sampel}

Sampel dalam penelitian ini berjumlah 60 responden.

\section{Jenis Penelitian}

Jenis penelitian yang dipakai adalah kuantitatif, dimana tujuannya adalah untuk mengetahui pengaruh antara variabel bebas terhadap variabel terikat baik parsial maupun simultan

\section{Metode Analisis Data}

Dalam menganalisis data digunakan uji instrumen, uji asumsi klasik, regresi, koefisien korelasi, koefisien determinasi dan uji hipotesis.

\section{HASIL PENELITIAN}

\section{Analisis Deskriptif}

Pada pengujian ini digunakan untuk mengetahui skor minimum dan maksimum, mean score dan standar deviasi dari masing-masing variabel. Adapun hasilnya sebagai berikut: 
Tabel 3. Hasil Analisis Descriptive Statistics Descriptive Statistics

\begin{tabular}{lr|r|r|r|r} 
& \multicolumn{2}{c}{ Descriptive Statistics } & & $\begin{array}{c}\text { Std. } \\
\text { Deviation }\end{array}$ \\
\hline Gaya Kepemimpinan (X1) & 60 & Minimum & Maximum & Mean & 4.213 \\
\hline Budaya Kerja (X2) & 60 & 28 & 48 & 37.32 & 3.838 \\
\hline Kinerja Karyawan (Y) & 60 & 31 & 47 & 37.18 & 38.37 \\
\hline Valid N (listwise) & 60 & & & & 3.645 \\
\hline
\end{tabular}

Gaya kepemimpinan diperoleh varians minimum sebesar 31 dan varians maximum 48 dengan mean score sebesar 37,32 dengan standar deviasi 4,213.

Budaya kerja diperoleh varians minimum sebesar 28 dan varians maximum 45 dengan mean score sebesar 37,18 dengan standar deviasi 3,838.

Kinerja karyawan diperoleh varians minimum sebesar 31 dan varians maximum 47 dengan mean score sebesar 38,37 dengan standar deviasi 3,645.

\section{Analisis Kuantitatif}

Pada analisis ini dimaksudkan untuk mengetahui pengaruh variabel independen terhadap variabel dependen. Adapun hasil pengujian sebagai berikut:

\section{a. Analisis Regresi Linier Berganda}

Uji regresi ini dimaksudkan untuk mengetahui perubahan variabel dependen jika variabel independen mengalami perubahan. Adapun hasil pengujiannya sebagai berikut:

\begin{tabular}{|c|c|c|c|c|c|c|}
\hline \multirow{3}{*}{\multicolumn{2}{|c|}{ Model }} & \multicolumn{2}{|c|}{ Coefficients $^{\mathrm{a}}$} & \multirow{3}{*}{$\begin{array}{c}\text { Standardized } \\
\text { Coefficients } \\
\text { Beta } \\
\end{array}$} & \multirow[b]{3}{*}{$\mathrm{t}$} & \multirow[b]{3}{*}{ Sig. } \\
\hline & & \multicolumn{2}{|c|}{$\begin{array}{l}\text { Unstandardized } \\
\text { Coefficients }\end{array}$} & & & \\
\hline & & $\mathrm{B}$ & Std. Error & & & \\
\hline 1 & (Constant) & 7.464 & 3.231 & & 2.310 & .025 \\
\hline & Gaya Kepemimpinan (X1) & .412 & .080 & .476 & 5.124 & .000 \\
\hline & Budaya Kerja (X2) & .418 & .088 & .440 & 4.730 & .000 \\
\hline
\end{tabular}

a. Dependent Variable: Kinerja Karyawan (Y)

Berdasarkan hasil pengujian pada tabel di atas, diperoleh persamaan regresi $\mathrm{Y}$ $=7,464+0,421 \mathrm{X} 1+0,418 \mathrm{X} 2$. Dari persamaan tersebut dijelaskan sebagai berikut:

1) Konstanta sebesar 7,464 diartikan jika gaya kepemimpinan dan budaya kerja tidak ada, maka telah terdapat nilai kinerja karyawan sebesar 7,464 point.

2) Koefisien regresi gaya kepemimpinan sebesar 0,421, angka ini positif artinya setiap ada peningkatan gaya kepemimpinan sebesar 0,421 maka kinerja karyawan juga akan mengalami peningkatan sebesar 0,421 point.

3) Koefisien regresi budaya kerja sebesar 0,418 , angka ini positif artinya setiap ada peningkatan budaya kerja sebesar 0,418 maka kinerja karyawan juga akan mengalami peningkatan sebesar 0,418 point.

\section{b. Analisis Koefisien Korelasi}

Analisis koefisien korelasi dimaksudkan untuk mengetahui tingkt kekuatan hubungan dari variabel independen terhadap variabel dependen baik secara parsial maupun simultan. Adapun hasil pengujian sebagai berikut: 
Tabel 5. Hasil Pengujian Koefisien Korelasi Gaya kepemimpinan Terhadap Kinerja Karyawan

Correlations $^{\text {b }}$

\begin{tabular}{llr|r} 
& & \multicolumn{1}{c}{$\begin{array}{c}\text { Gaya } \\
\text { Kepemimpinan } \\
(X 1)\end{array}$} & $\begin{array}{c}\text { Kinerja } \\
\text { Karyawan (Y) }\end{array}$ \\
\hline Gaya Kepemimpinan (X1) & Pearson Correlation & 1 & $.687^{* *}$ \\
\cline { 2 - 4 } & Sig. (2-tailed) & .000 \\
\hline Kinerja Karyawan (Y) & Pearson Correlation & $.687^{* *}$ & 1 \\
\cline { 2 - 5 } & Sig. (2-tailed) & .000 & \\
\hline
\end{tabular}

**. Correlation is significant at the 0.01 level (2-tailed).

b. Listwise $\mathrm{N}=60$

Berdasarkan hasil pengujian diperoleh nilai korelasi sebesar 0,687 artinya gaya kepemimpinan memiliki hubungan yang kuat terhadap kinerja karyawan.

Tabel 6. Hasil Pengujian Koefisien Korelasi Budaya kerja Terhadap Kinerja Karyawan

Correlations $^{\text {b }}$

\begin{tabular}{llr|r} 
& & $\begin{array}{c}\text { Budaya Kerja } \\
(\mathrm{X} 2)\end{array}$ & \multicolumn{1}{c}{$\begin{array}{c}\text { Kinerja } \\
\text { Karyawan (Y) }\end{array}$} \\
\hline Budaya Kerja (X2) & Pearson Correlation & 1 & $.668^{* *}$ \\
\cline { 2 - 4 } & Sig. (2-tailed) & & .000 \\
\hline Kinerja Karyawan (Y) & Pearson Correlation & $.668^{* *}$ & 1 \\
\cline { 2 - 4 } & Sig. (2-tailed) & .000 & \\
\hline
\end{tabular}

**. Correlation is significant at the 0.01 level (2-tailed).

b. Listwise $\mathrm{N}=60$

Berdasarkan hasil pengujian diperoleh nilai korelasi sebesar 0,668 artinya budaya kerja memiliki hubungan yang kuat terhadap kinerja karyawan.

Tabel 7. Hasil Pengujian Koefisien Korelasi Gaya kepemimpinan dan Budaya kerja secara simultan Terhadap Kinerja Karyawan.

Model Summary

\begin{tabular}{|c|c|c|c|c|}
\hline \multicolumn{5}{|c|}{ Model Summary } \\
\hline Model & $R$ & R Square & $\begin{array}{l}\text { Adjusted R } \\
\text { Square }\end{array}$ & $\begin{array}{l}\text { Std. Error of the } \\
\text { Estimate }\end{array}$ \\
\hline$\overline{1}$ & $.788^{\mathrm{a}}$ & .620 & .607 & 2.285 \\
\hline
\end{tabular}

a. Predictors: (Constant), Budaya Kerja (X2), Gaya Kepemimpinan (X1)

Berdasarkan hasil pengujian diperoleh nilai korelasi sebesar 0,788 artinya gaya kepemimpinan dan budaya kerja secara simultan memiliki hubungan yang kuat terhadap kinerja karyawan.

\section{c. Analisis Koefisien Determinasi}

Analisis koefisien determinasi dimaksudkan untuk mengetahui besarnya persentase pengaruh dari variabel independen terhadap variabel dependen baik secara parsial maupun simultan. Adapun hasil pengujian sebagai berikut:

Tabel 8. Hasil Pengujian Koefisien Determinasi Gaya kepemimpinan Terhadap

\section{Kinerja Karyawan}

Model Summary

\begin{tabular}{|c|c|c|c|c|}
\hline \\
\hline Model & $\mathrm{R}$ & R Square & $\begin{array}{l}\text { Adjusted R } \\
\text { Square }\end{array}$ & $\begin{array}{l}\text { Std. Error of the } \\
\text { Estimate }\end{array}$ \\
\hline 1 & $.687^{\mathrm{a}}$ & .471 & .462 & 2.673 \\
\hline
\end{tabular}

a. Predictors: (Constant), Gaya Kepemimpinan (X1)

Berdasarkan hasil pengujian diperoleh nilai determinasi sebesar 0,471 artinya gaya kepemimpinan memiliki kontribusi pengaruh sebesar $47,1 \%$ terhadap kinerja karyawan. 
Tabel 9. Hasil Pengujian Koefisien Determinasi Budaya kerja Terhadap Kinerja Karyawan. Model Summary

\begin{tabular}{|c|c|c|c|c|}
\hline \multicolumn{5}{|c|}{ Model Summary } \\
\hline Model & $\mathrm{R}$ & R Square & $\begin{array}{l}\text { Adjusted R } \\
\text { Square }\end{array}$ & $\begin{array}{l}\text { Std. Error of the } \\
\text { Estimate }\end{array}$ \\
\hline 1 & $.668^{\mathrm{a}}$ & .446 & .436 & 2.737 \\
\hline
\end{tabular}

Berdasarkan hasil pengujian diperoleh nilai determinasi sebesar 0,446 artinya budaya kerja memiliki kontribusi pengaruh sebesar 44,6\% terhadap kinerja karyawan.

Tabel 10. Hasil Pengujian Koefisien Determinasi Gaya kepemimpinan dan Budaya kerja Terhadap Kinerja Karyawan.

Model Summary

\begin{tabular}{l|c|c|cr} 
& & \multicolumn{2}{c}{ Model Summary } & \multicolumn{2}{c}{$\begin{array}{c}\text { Adjusted R } \\
\text { Sodel }\end{array}$} & \multicolumn{2}{c}{$\begin{array}{c}\text { Std. Error of the } \\
\text { Estimate }\end{array}$} \\
\hline 1 & R & R Square & Square & 2.285 \\
\hline
\end{tabular}

a. Predictors: (Constant), Budaya Kerja (X2), Gaya Kepemimpinan (X1)

Berdasarkan hasil pengujian diperoleh nilai determinasi sebesar 0,620 artinya gaya kepemimpinan dan budaya kerja secara simultan memiliki kontribusi pengaruh sebesar $62,0 \%$ terhadap kinerja karyawan, sedangkan sisanya sebesar $38,0 \%$ dipengaruhi faktor lain.

\section{d. Uji Hipotesis}

\section{Uji hipotesis Parsial (Uji t)}

Pengujian hipotesis dengan uji t digunakan untuk mengetahui hipotesis parsial mana yang diterima.

Hipotesis pertama: Terdapat pengaruh yang signifikan antara gaya kepemimpinan terhadap kinerja karyawan.

Tabel 11. Hasil Uji Hipotesis Gaya kepemimpinan Terhadap Kinerja Karyawan.

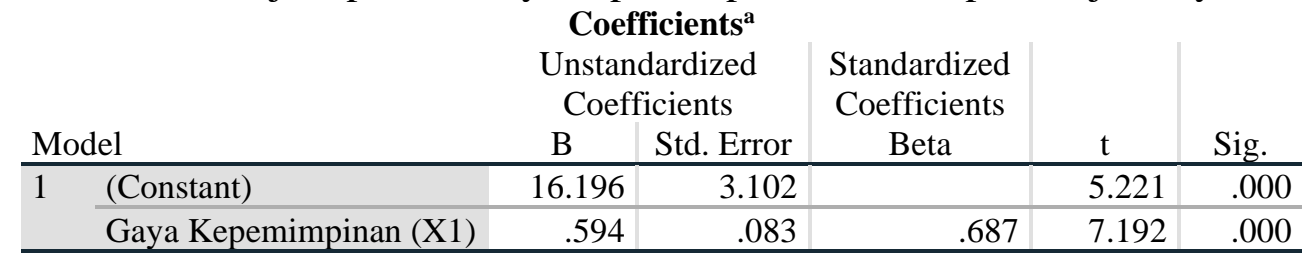

a. Dependent Variable: Kinerja Karyawan (Y)

Berdasarkan hasil pengujian pada tabel di atas, diperoleh nilai t hitung $>\mathrm{t}$ tabel atau $(7,192>2,002)$, dengan demikian hipotesis pertama yang diajukan bahwa terdapat pengaruh yang signifikan atara gaya kepemimpinan terhadap kinerja karyawan diterima.

Tabel 12. Hasil Uji Hipotesis Budaya kerja Terhadap Kinerja Karyawan. Coefficients $^{\mathrm{a}}$

\begin{tabular}{|c|c|c|c|c|c|c|}
\hline \multirow{3}{*}{\multicolumn{2}{|c|}{ Model }} & \multirow{2}{*}{\multicolumn{2}{|c|}{$\begin{array}{l}\text { Unstandardized } \\
\text { Coefficients }\end{array}$}} & \multirow{3}{*}{$\begin{array}{c}\text { Standardized } \\
\text { Coefficients } \\
\text { Beta }\end{array}$} & \multirow[b]{3}{*}{$\mathrm{t}$} & \multirow[b]{3}{*}{ Sig. } \\
\hline & & & & & & \\
\hline & & $\mathrm{B}$ & Std. Error & & & \\
\hline & (Constant) & 14.791 & 3.471 & & 4.262 & .000 \\
\hline & Budaya Kerja (X2) & .634 & .093 & 668 & 6.828 & .000 \\
\hline
\end{tabular}

a. Dependent Variable: Kinerja Karyawan (Y)

Berdasarkan hasil pengujian pada tabel di atas, diperoleh nilai t hitung $>\mathrm{t}$ tabel atau $(6,828>2,002)$, dengan demikian hipotesis kedua yang diajukan bahwa terdapat pengaruh yang signifikan atara budaya kerja terhadap kinerja karyawan diterima. 


\section{Uji Hipotesis Simultan (Uji F)}

Pengujian hipotesis dengan uji $\mathrm{F}$ digunakan untuk mengetahui hipotesis simultan yang mana yang diterima.

Hipotesis ketiga Terdapat pengaruh yang signifikan antara gaya kepemimpinan dan budaya kerja terhadap kinerja karyawan.

Tabel 13. Hasil Uji Hipotesis Gaya kepemimpinan dan Budaya kerja Terhadap Kinerja Karyawan

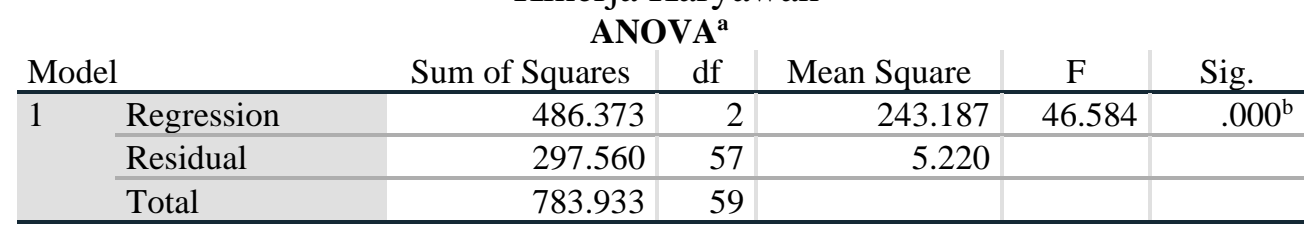

a. Dependent Variable: Kinerja Karyawan (Y)

b. Predictors: (Constant), Budaya Kerja (X2), Gaya Kepemimpinan (X1)

Berdasarkan hasil pengujian pada tabel di atas, diperoleh nilai $\mathrm{F}$ hitung $>\mathrm{F}$ tabel atau $(46,584>2,770)$, dengan demikian hipotesis ketiga yang diajukan bahwa terdapat pengaruh yang signifikan atara gaya kepemimpinan dan budaya kerja terhadap kinerja karyawan diterima.

\section{Pembahasan Hasil Penelitian}

\section{Pengaruh Gaya kepemimpinan Terhadap Kinerja Karyawan}

Gaya kepemimpinan berpengaruh signifikan terhadap kinerja karyawan dengan korelasi sebesar 0,687 atau memiliki hubungan yang kuat dengan kontribusi pengaruh sebesar 47,1\%. Pengujian hipotesis diperoleh nilai t hitung > t tabel atau (7,192 > 2,002 ). Dengan demikian hipotesis pertama yang diajukan bahwa terdapat berpengaruh signifikan antara gaya kepemimpinan terhadap kinerja karyawan diterima.

\section{Pengaruh Budaya kerja Terhadap Kinerja Karyawan}

Budaya kerja berpengaruh signifikan terhadap kinerja karyawan dengan korelasi sebesar 0,668 atau memiliki hubungan yang kuat dengan kontribusi pengaruh sebesar $44,6 \%$. Pengujian hipotesis diperoleh nilai $t$ hitung $>t$ tabel atau $(6,828>2,002)$. Dengan demikian hipotesis kedua yang diajukan bahwa terdapat berpengaruh signifikan antara budaya kerja terhadap kinerja karyawan diterima.

\section{Pengaruh Gaya kepemimpinan dan Budaya kerja Terhadap Kinerja Karyawan}

Gaya kepemimpinan dan budaya kerja berpengaruh signifikan terhadap kinerja karyawan dengan diperoleh persamaan regresi $\mathrm{Y}=7,464+0,421 \mathrm{X} 1+0,418 \mathrm{X} 2$, nilai korelasi sebesar 0,788 atau memiliki hubungan yang kuat dengan kontribusi pengaruh sebesar $62,0 \%$ sedangkan sisanya sebesar 38,0\% dipengaruhi faktor lain. Pengujian hipotesis diperoleh nilai $\mathrm{F}$ hitung $>\mathrm{F}$ tabel atau (46,584 > 2,770). Dengan demikian hipotesis ketiga yang diajukan bahwa terdapat berpengaruh signifikan antara gaya kepemimpinan dan budaya kerja terhadap kinerja karyawan diterima.

\section{KESIMPULAN DAN SARAN}

\section{Kesimpulan}

a. Gaya kepemimpinan berpengaruh signifikan terhadap kinerja karyawan dengan kontribusi pengaruh sebesar $47,1 \%$. Uji hipotesis diperoleh nilai t hitung $>t$ tabel atau $(7,192>2,002)$.

b. Budaya kerja berpengaruh signifikan terhadap kinerja karyawan dengan kontribusi pengaruh sebesar 44,6\%. Uji hipotesis diperoleh nilai t hitung $>\mathrm{t}$ tabel atau $(6,828>$ 
2,002).

c. Gaya kepemimpinan dan budaya kerja berpengaruh signifikan terhadap kinerja karyawan dengan kontribusi pengaruh sebesar 62,0\% sedangkan sisanya sebesar $38,0 \%$ dipengaruhi faktor lain. Uji hipotesis diperoleh nilai $\mathrm{F}$ hitung $>\mathrm{F}$ tabel atau $(46,584>2,770)$.

\section{Saran}

a. Pimpinan harus memberikan rangsangan dan dorongan kepada karyawan agar lebih memiliki semangat kerja yang optimal.

b. Variabel budaya kerja, pernyataan yang paling lemah adalah pernyataan nomor 5 yaitu perusahaan hanya mementingkan dan memperhatikan pekerjaan yang dilakukan karyawan dimana hanya mencapai score sebesar 3,67 meskipun termasuk dalam kategori baik namun untuk lebih baik lagi perusahaan harus lebih konsisten menerapkan aturan yang dibuat sehingga karyawan dapat benar-benar bekerja sesuai dengan keahlian yang di miliki agar dapat menghasilkan kinerja karyawan yang maksimal.

c. Perusahaan harus memperhatikan kedisiplinan karyawan dalam menjaga ketepatan waktu dan juga dalam hasil kualitas pekerjaan karyawan dengan meningkatkan meningkatkan disiplin kerja dan gaya kepemimpinan.

d. Kontibusi pengaruh antara gaya kepemimpinan dan budaya kerja secara simultan terhadap kinerja karyawan karyawan sebesar $62,0 \%$, nilai ini masih bisa ditingkatkan serta kondisi masing-masing variabel bebas harus ditingkatkan secara signifikan. Oleh karenanya disarankan kepada penelitian berikutnya agar melakukan penelitian yang relevan dengan cara memperbaiki indikator yang masih tidak baik atau dengan menambah indikator pertanyaan dan jumlah responden penelitian sehingga akan dapat lebih diketahui variabel yang paling memberikan kontribusi positif bagi perusahaan.

\section{DAFTAR PUSTAKA}

Abdullah, M (2014) Manajemen dan Evaluasi Kinerja Karyawan, Yogyakarta: Penerbit Aswaja Pressindo.

Abid, M., \& Andi, D. (2020). Pengaruh Gaya Kepemimpinan Dan Kompensasi Terhadap Kepuasan Kerja Karyawan PT. Citra Rasa Betawi. JENIUS (Jurnal Ilmiah Manajemen Sumber Daya Manusia), 4(1), 11-21.

Dessler, G. (2006.) Manajemen Sumber Daya Manusia (Jilid II). Jakarta: Indeks.

George Terry R \& Rue, Leslie W. Rue (2016) Dasar-Dasar Manajemen, Jakarta Bumi Aksara.

Gerry Dessler (2016) Human Resources Management, Prenticehall, London: International Inc.

Hasibuan, Malayu S.P. (2016). Manajemen Sumber Daya Manusia. Edisi Revisi. Jakarta: PT Bumi Aksara.

Imam Ghozali (2017). “Aplikasi Analisis Multivariate Dengan Program SPSS”. Edisi Kelima. Semarang: Badan Penerbit Undip.

Istijanto (2014) “Riset Sumber Daya Manusia”. Jakarta: PT. Gramedia Pustaka

Khoiriah, N., \& Karmiyati, S. (2020). Pengaruh Pengetahuan Dan Tingkat Pendidikan Terhadap Motivasi Masyarakat Dalam Pembayaran Pajak Bumi Dan Bangunan. JENIUS (Jurnal Ilmiah Manajemen Sumber Daya Manusia), 4(1), 80-95.

Luthans Fred (2014) Organizational Behavior, Ney York: McGraw-Hill, New York.

Mangkunegara, Prabu Anwar. (2016). Evaluasi Kinerja SDM. Cetakan ke tujuh, PT Refika Aditama: Bandung. 
Muslimat, A., \& Ab Wahid, H. (2021). Pengaruh Disiplin Kerja Terhadap Kinerja Karyawan Pada PT. Pos Indonesia Kantor Cipondoh. JENIUS (Jurnal Ilmiah Manajemen Sumber Daya Manusia), 4(2), 120-127.

Nurjaya, N., Affandi, A., Ilham, D., Jasmani, J., \& Sunarsi, D. (2021). Pengaruh Kompetensi Sumber Daya Manusia Dan Kemampuan Pemanfaatan Teknologi Terhadap Kinerja Aparatur Desa Pada Kantor Kepala Desa Di Kabupaten Gunungkidul, Yogyakarta. JENIUS (Jurnal Ilmiah Manajemen Sumber Daya Manusia), 4(3), 332-346.

Prasetiyani, D., \& Nariah, N. (2020). Urgensi Kinerja Guru SMK Via Medika Melalui Peningkatan Kompetensi Dan Motivasi Kerja. JENIUS (Jurnal Ilmiah Manajemen Sumber Daya Manusia), 4(1), 41-50.

Rawi, R. D. P., \& Kadir, M. A. A. (2018). Analisis Hubungan Motivasi Terhadap Kinerja Pegawai (Studi Kasus Pada Kantor Wali Kota Sorong Papua Barat). Manajemen Dewantara, 2(2), 87-94.

Robbins, P.S, \& Judge, A.T. (2003). Organizational Behavior. Jakarta: Salemba Empat. Sugiyono (2017), "Metode Penelitian Administrasi : dilengkapi dengan Metode $R \&$ $D$ ”. Bandung: Alfabeta.

Sunarsi, D. (2019). Penerapan MSDM Strategis Dalam Upaya Meningkatkan Kemampuan Organisasi dalam menyongsong Revolusi 4.0. Jurnal Ilmiah MEA (Manajemen, Ekonomi, \& Akuntansi), 3(1), 221-233.

Veithzal Rivai (2015) Manajemen Sumber Daya Manusia Untuk Perusahaan, Jakarta: Raja Grafindo Persada.

Wibowo (2015) Manajemen Kinerja, Jakarta: PT. Raja Grafindo Persada 